\title{
STUDY OF CORD BLOOD NUCLEATED RED BLOOD CELLS/100 WBC COUNT AS A PREDICTOR OF PERINATAL ASPHYXIA AND ITS SEVERITY
}

\author{
K. Goutami Ratna ${ }^{1}$, M. Chowdary Babu², T. Ramesh Babu³, S. Bharati4, Vani Padmaja ${ }^{5}$, Annapurna Sirisha ${ }^{6}$ \\ 1 Post Graduate, Department of Paediatrics, Gandhi Medical College, Secunderabad, Telangana. \\ ${ }^{2}$ Assistant Professor, Department of Paediatrics, Gandhi Medical College, Secunderabad, Telangana. \\ ${ }^{3}$ Professor, Department of Paediatrics, Gandhi Medical College, Secunderabad, Telangana. \\ ${ }^{4}$ Assistant Professor, Department of Paediatrics, Gandhi Medical College, Secunderabad, Telangana. \\ ${ }^{5}$ Associate Professor, Department of Pathology, Gandhi Medical College, Secunderabad, Telangana. \\ ${ }^{6}$ Assistant Professor, Department of Pathology, Gandhi Medical College, Secunderabad, Telangana.
}

\section{ABSTRACT}

Perinatal asphyxia is a major cause of neonatal mortality and chronic neurologic disability amongst survivors. There is no single parameter to define perinatal asphyxia. Recent studies have established a correlation between cord blood nucleated red blood cell count and severity of perinatal asphyxia.

\section{AIMS AND OBJECTIVES}

To evaluate the utility of cord blood nucleated red blood cell/100 WBC count in early identification of perinatal asphyxia and in predicting its severity.

\section{MATERIALS AND METHOD}

This is a case-control study with a total number of 100 subjects, out of which 50 are asphyxiated/case group and the other 50 are non-asphyxiated/control group, which include neonates born in Gandhi Hospital in the Department of Obstetrics and Gynecology. Immediately after birth, umbilical cord blood is collected and a thin blood smear slide is prepared which is stained with Leishman stain for NRBC count. The NRBC count of the case group and the control group is compared. The results were analyzed statistically.

\section{RESULTS}

The mean NRBC count in case group was 38.3 and that in control group was 5.24 with significant rise in cord blood NRBC/100 WBC count in case group compared to controlled group with p value $<0.001$. Increase in NRBC/100 WBC count was also associated with increased severity of HIE in case group.

\section{CONCLUSION}

In conditions where blood gas analyzers are not easily available, cord blood NRBC count can be used as a cheaper and reliable alternative to predict perinatal asphyxia and to assess its severity.

\section{KEYWORDS}

Perinatal Asphyxia, Nucleated Red Blood Cells, Cord Blood.

HOW TO CITE THIS ARTICLE: K. Goutami Ratna, M. Chowdary Babu, T. Ramesh Babu, S. Bharati, Vani Padmaja, Annapurna Sirisha. "Study of Cord Blood Nucleated Red Blood Cells/100 WBC Count as a Predictor of Perinatal Asphyxia and its Severity." Journal of Evolution of Medical and Dental Sciences 2015; Vol. 4, Issue 95, November 26; Page: 16087-16089, DOI: $10.14260 /$ jemds/2015/2351.

\section{INTRODUCTION}

Perinatal asphyxia is the most important and common cause of preventable cerebral injury occurring in the neonatal period. In spite of major advances in monitoring technology and knowledge of fetal and perinatal medicine, perinatal asphyxia remains as one of the significant causes of mortality and long-term morbidity. In India, between 250,000-350,000 infants die each year due to birth asphyxia. ${ }^{1}$

Financial or Other, Competing Interest: None.

Submission 26-10-2015, Peer Review 27-10-2015,

Acceptance 16-11-2015, Published 26-11-2015.

Corresponding Author:

Dr. K. Goutami Ratna,

Flat No. 301, DR Apartments,

Padmaraonagar,

Secuderabad-500025

Telangana.

E-mail: gouthamiratna8@gmail.com

DOI:10.14260/jemds/2015/2351.
WHO has defined perinatal asphyxia as a "Failure to initiate and sustain breathing at birth."2 American Academy of Pediatrics (AAP) and American College of Obstetrics and Gynaecology (ACOG) define perinatal asphyxia when all the following criterias are met. ${ }^{3}$

1. Profound metabolic or mixed acidemia $(\mathrm{pH}<7.00)$ in an umbilical arterial blood sample.

2. Apgar score of 0-3 > $5 \mathrm{~min}$. after birth.

3. Neonatal encephalopathy (e.g., Seizures, coma, hypotonia).

4. Multiple organ involvement (Kidney, lungs, liver, heart, intestines).

Hypoxic Ischemic Encephalopathy (HIE) refers to the CNS dysfunction associated with perinatal asphyxia. HIE is of foremost concern in an asphyxiated neonate because of its potential to cause serious long-term neuromotor sequelae among survivors. A detailed classification of HIE (Stage I, Stage II and Stage III) in term neonates was proposed by Sarnat and Sarnat. ${ }^{4}$ 
Parameters that have been used to predict or define perinatal asphyxia include: Intrapartum electronic fetal monitoring, fetal or umbilical cord $\mathrm{pH}$ measurement, meconium-stained amniotic fluid, Apgar score, Hypoxic Ischemic Encephalopathy (HIE), and major organ disorder. However, no single marker of perinatal asphyxia has shown good predictive efficiency and only a combination of various indices can help in the early diagnosis of perinatal asphyxia.

NRBC counts in umbilical venous blood of neonates have been reported as a possible marker of perinatal asphyxia.5,6 Many acute and chronic stimuli cause increases in the number of circulating nRBCs from either increased erythropoietic activity or a sudden release from the marrow storage pools. ${ }^{7}$ Previously reported causes of a high NRBC count include: Prematurity, ABO or Rh incapability, maternal diabetes, intrauterine growth retardation, acute asphyxia, congenital infection, cyanotic heart disease, pre-eclampsia, maternal smoking, and chorioamnionitis. ${ }^{8}$

The hypoxic event induces a compensatory response in the form of exaggerated erythropoiesis resulting in the release of immature red blood cells into the fetal circulation. The number of NRBC/100 WBC is variable but is rarely greater than 10 in normal neonates. ${ }^{9,10}$ Our study attempts to evaluate the predictability of presence and severity of perinatal asphyxia with the help of cord blood NRBC/100 WBC count and also to assess its sensitivity and specificity in diagnosing perinatal asphyxia.

\section{AIMS AND OBJECTIVES}

1. To assess the nucleated red blood cell/100 WBC count in cord blood of a group of asphyxiated neonates.

2. To evaluate the utility of cord blood nucleated red blood cell/100 WBC count in early identification of perinatal asphyxia.

3. To determine its predictive value for severity and shortterm outcome of perinatal asphyxia.

\section{MATERIALS AND METHODS}

A case controlled study, which includes 50 cases and 50 controls was designed. The study group includes the babies born to mothers who delivered in Gandhi Hospital, and satisfying the inclusion criteria for cases and controls. Neonates born at 37-42 weeks of gestation with thick meconium staining of liquor, signs of fetal distress and/or Apgar at 1 and $5 \mathrm{~min}<7$ are included in the case group. Nonasphyxiated newborns born at 37-42 weeks of gestation with Apgar score $>7$ at both 1 and 5 min. clear amniotic fluid and normal neurologic evaluation during the $1^{\text {st }}$ week are included in the control group. Neonates born to mothers with pre-eclamptic toxemia, diabetes mellitus, Rh-sensitization and chorioamnionitis; born at preterm; with birth weight $<2500$ (IUGR) are excluded from the study.

Immediately after birth, umbilical cord blood is collected from doubly clamped cord in EDTA bottle. A slide is prepared which is stained with leishman stain. The slides wre then studied for NRBC/100 WBC count. The subjects were followed up till discharge from the hospital or death of the subject. Detection and staging of HIE among the asphyxiated group was done according to the Sarnat and Sarnat staging.

The nRBC count of the case group and the control group is compared. The $\mathrm{nRBC}$ count of subjects belonging to different stages of HIE is then compared.
The results were analyzed statistically. The Chi square test/fisher exact test were applied to study the association between the variables as appropriate.

\section{PERIOD OF STUDY}

This study was conducted from January 2015 to August 2015.

\section{RESULTS}

There was no significant difference between case group and control group in terms of maternal age, parity, mode of delivery, sex of the newborn and birth weight. (Table - 1)

\begin{tabular}{|c|c|c|c|}
\hline Parameters & Cases & Controls & $\begin{array}{c}\text { P } \\
\text { value }\end{array}$ \\
\hline $\begin{array}{c}\text { Maternal age (in } \\
\text { yrs) }\end{array}$ & $23.6 \pm 5.5$ & $23.7 \pm 4.7$ & 0.92 \\
\hline Parity (P/M) & $26 / 24$ & $23 / 27$ & 0.27 \\
\hline $\begin{array}{c}\text { Mode of delivery } \\
\text { (V/L) }\end{array}$ & $32 / 18$ & $29 / 21$ & 0.44 \\
\hline Gender (M/F) & $29 / 21$ & $28 / 22$ & 0.42 \\
\hline $\begin{array}{c}\text { Mean birth weight } \\
\text { (in grams) }\end{array}$ & $2.83 \pm 0.55$ & $2.89 \pm 0.55$ & 0.58 \\
\hline \multicolumn{4}{|c|}{ Table 1: Comparison of Variables between } \\
\hline
\end{tabular}

P - Primipara; M- multipara; V - vaginal delivery; L - LSCS; M - male; F - female.

There was a significant rise in NRBC count in case group as compared to control group. The mean NRBC count among cases was 38.3, whereas that of controls was 5.24. (Table 2 and Table 3).

\begin{tabular}{|c|c|c|c|}
\hline & Cases & Controls & Total \\
\hline $\begin{array}{c}\text { Positive } \\
(\text { NRBC/100WBC >10) }\end{array}$ & 44 & 5 & 49 \\
\hline $\begin{array}{c}\text { Negative } \\
\text { (NRBC/100WBC <10) }\end{array}$ & 06 & 45 & 51 \\
\hline Total & $\mathbf{5 0}$ & $\mathbf{5 0}$ & $\mathbf{1 0 0}$ \\
\hline \multicolumn{4}{|c}{ Table 2 } \\
\hline
\end{tabular}

P value $-<0.001$

\begin{tabular}{|c|c|c|}
\hline & Cases & Controls \\
\hline Mean NRBC/100 WBC count & 38.3 & 5.24 \\
\hline Range & $6-103$ & $1-18$ \\
\hline \multicolumn{2}{|c|}{ Table 3: Mean NRBC Count in Cases and Controls } \\
\hline
\end{tabular}

$\mathrm{P}$ value $-<0.001$

The rise in NRBC count was also noted to be more as the severity of the HIE increases. (Table 4)

\begin{tabular}{|c|c|c|c|}
\hline Stages of HIE & HIE I & HIE II & HIE III \\
\hline POSITIVE & 10 & 23 & 9 \\
\hline NEGATIVE & 4 & 1 & 0 \\
\hline TOTAL & 14 & $\mathbf{2 4}$ & $\mathbf{9}$ \\
\hline Mean NRBC/100 WBC & $\mathbf{1 7 . 9}$ & $\mathbf{3 8 . 8 7}$ & $\mathbf{7 7 . 3 3}$ \\
\hline \multicolumn{4}{|c|}{ Table 4: Mean NRBC Count Among the Cases } \\
\hline
\end{tabular}

HIE - hypoxic ischemic encephalopathy; P value - $<0.001$

\begin{tabular}{|c|c|c|}
\hline NRBC/100 WBC Count & Cases & Controls \\
\hline $0-10$ & 06 & 45 \\
\hline $11-50$ & 31 & 5 \\
\hline $51-100$ & 12 & 0 \\
\hline $101-150$ & 1 & 0 \\
\hline Total & $\mathbf{5 0}$ & $\mathbf{5 0}$ \\
\hline Mean NRBC/100 WBC & $\mathbf{3 8 . 3}$ & $\mathbf{5 . 2 4}$ \\
\hline Table 5: Distribution of NRBC's in Cases and Controls \\
\hline
\end{tabular}




\section{CONCLUSION}

In our study, cord blood NRBC/100 WBC count is found to be helpful in early identification of HIE and in predicting its severity with a sensitivity of $88 \%$ and specificity of $90 \%$. The positive predictive value was found to be $89.7 \%$ and the negative predictive value was $88.2 \%$. Hence, we conclude that cord blood NRBC/100 WBC count is a reliable marker for diagnosing perinatal asphyxia and also in predicting its severity. In the centers where blood gas analyzers are not easily available, it is a reliable and less expensive alternative to predict the severity of perinatal asphyxia.

\section{REFERENCES}

1. NNPD network. National Neonatal Perinatal Databasereport for the year 2002-2003. NNF NNPD network. New Delhi: 2005.

2. World Health Organization. Neonnatal and Perinatal Mortality; Country, Regional and Global estimates, 2004; WHO, Geneva 2006;1-25.

3. Cloherty JP, Eichenwald EC, Hansen AR, Stark AR. Perinatal asphyxia and hypoxic-ischemic encephalopathy. (Chapter 55). In: Manual of Neonatal Care. 7th edition, Wolter Kluwer, Lippincott Williams \& Wilkins: Philadelphia USA 2011;p.713-26.
4. Sarnat HB, Sarnat MS: Neonatal encephalopathy following fetal distress: A clinical and electroencephalographic study. Arch Neurol 33:695-706, 1976.

5. Green DW, Mimouni F. Nucleated erythrocytes in healthy infants and in infants of diabetic mothers. J Pediatr 1990;116(1):129-31.

6. Ghosh B, Mittal S, Kumar S, Dadhwal V. Prediction of perinatal asphyxia with nucleated red blood cells in cord blood of newborns. Int J Gynaecol Obstet.

7. 2003;81:267-271.

8. Ruth V, Fyhrquist F, Clemons G. Cord plasma vasopressin, erythropoietin and hypoxanthine as indices of asphyxia at birth. Pediatr Res. 1988;24:490-494.

9. M C Hermansen Arch Dis Child Fetal Neonatal Ed 2001;84:F211-F215

10. Phelan JP, Ahn MO, Korst LM, Martin GI. Nucleated red blood cells: a marker for fetal asphyxia? Am J Obstet Gynecol 1995;173(5):1380-4.

11. McCarthy JM, Capullari T, Thompson Z, Zhu Y, Spellacy WN. Umbilical cord nucleated red blood cell counts: normal values and the effect of labor. J Perinatol. 2006;26:89-92. 